\title{
Synthesis and Optical Properties of Water-Soluble NIR Absorbing Star Polypeptides based on Functional Rylene Dyes
}

\author{
Juan Rodríguez-Hernández, Jianqiang Qu, Erik Reuther, Harm-Anton Klok ${ }^{1,}(\Xi)$ \\ and Klaus Müllen (ه) \\ Max Planck Institute for Polymer Research, Ackermannweg 10, 55128 Mainz, Germany \\ E-mail: muellen@ompip-mainz.mpg.de (K.M.) \\ ${ }^{1}$ École Polytechnique Fédérale de Lausanne, Institut des Matériaux, Laboratoire des \\ Polymères, Bâtiment MX-D, 1015 Lausanne, Switzerland \\ E-mail: harm-anton.klok@epfl.ch (H.-A.K)
}

Received: 5 March 2004/ Accepted: 23 March 2004

\section{Summary}

In this contribution, the synthesis of two novel amino-functionalized terrylene and quaterrylene diimide derivatives is described. These chromophores have been used as initiators for the ring-opening polymerization of $\mathrm{N}^{\varepsilon}$-benzyloxycarbonyl-L-lysine $\mathrm{N}$ carboxyanhydride. 4-Arm star polypeptides were obtained with number average chain lengths of 50 and 100 units. Removal of the $\mathrm{N}^{\varepsilon}$-benzyloxycarbonyl side-chain protective groups afforded unprecedented water-soluble terrylene and quaterrylene based star polypeptides that combined high extinction coefficients in the NIR range with very good chemical and photostability.

\section{Introduction}

The synthesis of novel near-infrared (NIR) absorbing dyes has attracted the attention of many research groups due to potential applications, for example in optical recording media, thermally written displays, laser printers or as laser filters.[1] Near-infrared absorbing organic compounds have also been successfully employed in the medical field, mainly as sensitizers in photodynamic therapy.[1] A major drawback of most NIR dyes, however, is their limited photostability.

Perylene is the most important representative among the rylene dyes and has been broadly used as commercial dye and as a pigment.[2] Extension of the perylene aromatic $\pi$-system with one or two naphthalene units results in terrylene, respectively, quaterrylene dyes. In comparison with perylene, the absorption maxima of terrylene and quaterrylene are bathochromically shifted to the NIR region.[3] In contrast to commercially available NIR absorbers such as cyanines, phtalocyanines or metal dithiolenes, rylene chromophores exhibit high thermal, chemical and photostability.[3] 
In this contribution, we will describe the synthesis of two novel tetra-amino functionalized terrylene and quaterrylene derivatives. The amino function will be employed as initiator for the ring-opening polymerization of $\mathrm{N}^{\mathrm{E}}$-benzyloxycarbonyl-L-Lysine $\mathrm{N}$ carboxyanhydride (Z-Lys NCA) to produce star polypeptides of different chain lengths. The optical properties in organic media and, after removal of the lysine side chain protective groups, in aqueous solution will be reported. The photostability in water will be analyzed as well. As previously mentioned, such rylene-polypeptide hybrids may be of interest, for example in the medical field for tumor therapy or tissue imaging, or as sensitizers for photodynamic therapy.[4]

\section{Experimental part}

\section{Materials}

The synthesis of $\mathrm{N}, \mathrm{N}$ '-bis-(2,6-diisopropylphenyl)-1,6,9,14-tetrabromo terrylene3,4,10,11-tetracarboxylic acid diimide (1) and N,N'-bis-(2,6-diisopropylphenyl)1,6,8,11,16,18-hexabromoquaterrylene-3,4,13,14-tetracarboxylic acid diimide (6) will be reported separately.[5] $\mathrm{N}$-(tert-Butyloxycarbonyl) tyramine (3) was prepared according to a literature procedure.[6] Z-Lys NCA was synthesized using the method described by Poché et al.[7] N,N'-Dimethylformamide (DMF) was distilled from $\mathrm{CaH}_{2}$ under reduced pressure and subsequently stored over molecular sieves $(4 \AA)$ under an argon atmosphere. All other solvents and reagents were purchased from commercial suppliers and were used as received.

\section{Physical and analytical methods}

${ }^{1} \mathrm{H}$ and ${ }^{13} \mathrm{C}-\mathrm{NMR}$ spectra were recorded on Bruker AMX 250, AC300 and AMX 500 spectrometers, using the residual proton resonance or the carbon signal of the deuterated solvent as the internal standard. Elemental analysis was performed on a Foss Heraeus Vario EL apparatus. Field desorption (FD) mass spectra were recorded on a VG Instruments ZAB 2-SE-FDP spectrometer. Ultraviolet-visible (UV-vis) spectra were recorded on a Perkin-Elmer Lambda 9 spectrometer. Gel permeation chromatography (GPC) was performed at $60^{\circ} \mathrm{C}$ with a setup consisting of a Waters 510 pump and a series of three styrene-divinylbenzene (SDV) columns $(300 \times 8 \mathrm{~mm})$ with pore sizes of $500,10^{5}$ and $10^{6} \AA$ (Polymer Standards Service, Mainz, Germany). A 0,1 M solution of LiBr in DMF was used as the mobile phase, and the elution of the samples was monitored with refractive-index $(\mathrm{RI})$ detection. Elution times were converted to molecular weights with a calibration curve constructed from narrow polydispersity poly(ethylene oxide) standards.

\section{Procedures}

$N, N^{\prime}$-Bis-(2,6-diisopropylphenyl)-1,6,9,14-tetra[4-(2-N-tert-butoxycarbonylaminoethyl)phenoxy] terrylene-3,4,10,11-tetracarboxylic acid diimide (4). In a $250-\mathrm{mL}$ flask, $500 \mathrm{mg}(0,59 \mathrm{mmol})$ of 1 was dissolved at $80^{\circ} \mathrm{C}$ in $30 \mathrm{~mL}$ of N-methyl-2pyrrolidone. Then, $332 \mathrm{mg}(2,4 \mathrm{mmol})$ of $\mathrm{K}_{2} \mathrm{CO}_{3}$ and $1.12 \mathrm{~g}(4,71 \mathrm{mmol})$ of 3 were added and the mixture heated to $90^{\circ} \mathrm{C}$ overnight under an argon atmosphere. After that, the product was cooled to room temperature and poured into a mixture of $100 \mathrm{~mL}$ methanol and $30 \mathrm{~mL}$ of a $5 \%$ aqueous solution of citric acid. The resulting precipitate was filtered and washed with water until the filtrate became neutral. Final purification was done by 
column chromatography ( $1 / 1 \mathrm{v} / \mathrm{v} \mathrm{CH}_{2} \mathrm{Cl}_{2}$ /acetone). Yield $400 \mathrm{mg}(80 \%) .{ }^{1} \mathrm{H}-\mathrm{NMR}(500$ $\left.\mathrm{MHz}, \mathrm{C}_{2} \mathrm{D}_{2} \mathrm{Cl}_{4}, \delta\right): 9.45(\mathrm{~s}, 4 \mathrm{H}$; terrylene), 8.14 (s, $4 \mathrm{H}$; terrylene), 7.32 (t, $2 \mathrm{H}$; terrylene), $7.17(\mathrm{~m}, 12 \mathrm{H} ; \mathrm{Ph}-\mathrm{H}), 7.11(\mathrm{~m}, 8 \mathrm{H} ; \mathrm{Ph}-\mathrm{H}), 4.59(\mathrm{~s}, 4 \mathrm{H} ; \mathrm{Ph}-\mathrm{H}), 3.28\left(\mathrm{~b}, 8 \mathrm{H} ; \mathrm{CH}_{2}\right), 2.72(\mathrm{~m}$, $8 \mathrm{H} ; \mathrm{CH}_{2}$ ), 2.53 (s, 4H; CH-isopropyl), 1.33 (s, 36H; $\mathrm{CH}_{3}$-tert.-butyl), 1.02 (d, 24H; $\mathrm{CH}_{3}$ isopropyl). ${ }^{13} \mathrm{C}-\mathrm{NMR}\left(125 \mathrm{MHz}, \mathrm{C}_{2} \mathrm{D}_{2} \mathrm{Cl}_{4}, \delta\right): 164.18(\mathrm{C}=\mathrm{O}), 156.92(\mathrm{C}=\mathrm{O}), 156.13$, $155.11,146.86,137.14,132.46,132.04,131.87,130.74,130.20,130.11,126.94,125.03$, $123.93,123.22,120.99,80.42,55.45,36.95,29.24,28,65,24.35 . \mathrm{MS} \mathrm{m} / \mathrm{z}(\mathrm{FD}, 8 \mathrm{kV})$ : $1776.11(100 \%)[\mathrm{M}+]$. Elem. Anal. Calcd. For $\mathrm{C}_{110} \mathrm{H}_{114} \mathrm{~N}_{6} \mathrm{O}_{6}: \mathrm{C}, 74.39 \% ; \mathrm{H}, 6,47 \% ; \mathrm{N}$, 4.73\%. Found: C, 75.36\%; H, 6.49\%; N, 4.72\%. UV-vis $\left(\mathrm{CHCl}_{3}\right): \lambda_{\max } / \mathrm{nm}\left(\varepsilon / \mathrm{M}^{-1} \mathrm{~cm}^{-1}\right)$ : $677\left(125.000 \mathrm{M}^{-1} \mathrm{~cm}^{-1}\right)\left(\mathrm{CHCl}_{3}\right)$.

$N, N$ '-Bis-(2,6-diisopropylphenyl)-1,6,9,14-tetra[4-(2-aminoethyl)phenoxy]terrylene$3,4,10,11$-tetracarboxylic acid diimide (5). In a $250-\mathrm{mL}$ flask, $5.00 \mathrm{~g}(3.03 \mathrm{mmol})$ of 4 was dissolved in $60 \mathrm{~mL}$ of $\mathrm{CH}_{2} \mathrm{Cl}_{2}$. The solution was cooled to $0^{\circ} \mathrm{C}$, and $60 \mathrm{~mL}$ of $\mathrm{CF}_{3} \mathrm{COOH}$ were carefully added under stirring. The mixture was allowed to warm to room temperature and stirred for $1 \mathrm{~h}$. Then, the solvent was removed under reduced pressure. The residue was dissolved in $\mathrm{CH}_{2} \mathrm{Cl}_{2}$ and the resulting solution was treated with $100 \mathrm{~mL}$ of $5 \%$ aqueous solution sodium carbonate. The organic phase was separated, washed with water, and dried over sodium sulphate. The product was obtained after the solvent was removed in vacuo. Yield 4,1 g (100\%). ${ }^{1} \mathrm{H}-\mathrm{NMR}\left(500 \mathrm{MHz}, \mathrm{CH}_{2} \mathrm{Cl}_{2}, \delta\right): 9.36(\mathrm{~s}, 4 \mathrm{H}$; terrylene), 8.27 (s, $4 \mathrm{H}$; terrylene), $7.76(\mathrm{~d}, 8 \mathrm{H}$; terrylene), $7.47(\mathrm{t}, 2 \mathrm{H} ; \mathrm{Ph}-\mathrm{H}), 7.32(\mathrm{~d}, 4 \mathrm{H} ; \mathrm{Ph}-\mathrm{H})$, 6.94(d, $8 \mathrm{H} ; \mathrm{Ph}-\mathrm{H}$ ), 3.20 (b, $8 \mathrm{H} ; \mathrm{CH}_{2}$ ), $2.75\left(\mathrm{~m}, 8 \mathrm{H} ; \mathrm{CH}_{2}\right), 2.6$ (s, $4 \mathrm{H} ; \mathrm{CH}$ isopropyl), 1.05 (d, 24H; $\mathrm{CH}_{3}$ isopropyl). ${ }^{13} \mathrm{C}-\mathrm{NMR}$ (166 MHz, $\mathrm{C}_{2} \mathrm{D}_{2} \mathrm{Cl}_{4}$, spinecho, $\delta$ ): 160.05, 152.78, $151.96,150.74,142.43,132.92,128.16,128.01,127.57,126.43,125.93,122.59,120.5$, $119.56,119.42,118.75,117.10,76.19,50.77,38.76,32.66,25.20,21.14 . \mathrm{MS} \mathrm{m} / \mathrm{z}$ (FD, 8kV): $1375.65(100 \%)[\mathrm{M}+]$. Elem. Anal. Calcd. for $\mathrm{C}_{90} \mathrm{H}_{82} \mathrm{~N}_{6} \mathrm{O}_{8}: \mathrm{C}, 78.58 \% ; \mathrm{H}, 6.01 \%$; $\mathrm{N}, 6.11 \%$. Found: $\mathrm{C}, 78.63 \% ; \mathrm{H}, 6,72 \% ; \mathrm{N}, 6,17 \%$. UV-vis $\left(\mathrm{CHCl}_{3}\right): \lambda_{\max } / \mathrm{nm}\left(\varepsilon / \mathrm{M}^{-1} \mathrm{~cm}^{-1}\right)$ : $677\left(81.850 \mathrm{M}^{-1} \mathrm{~cm}^{-1}\right)\left(\mathrm{CHCl}_{3}\right)$.

$N, N^{\prime}$-Bis-(2,6-diisopropylphenyl)-9,18(or 19)-dibromo-1,6,11,16-tetra[4-(2-N-tertbutoxycarbonyl)-aminoethyl)phenoxy]quaterrylene-3,4,13,14-tetracarboxylic acid dimide (7). The synthesis of 7 was carried out using the same procedure as for 4 . In this case, however, an 8-fold excess of 3 relative to 6 was employed. Final purification proceeded as for the terrylene analog using $\left(1 / 1 \mathrm{v} / \mathrm{v} \mathrm{CH}_{2} \mathrm{Cl}_{2}\right.$ /acetone) for column chromatography. Yield: $65 \%$. ${ }^{1} \mathrm{H}-\mathrm{NMR}\left(500 \mathrm{MHz}, \mathrm{CDCl}_{3}, \delta\right.$ ): 9,75 (d, 2H; quaterrylene), 9,44 (m, $2 \mathrm{H}$; quaterrylene), $9,16(\mathrm{~m}, 2 \mathrm{H}$; quaterrylene), 8,22 (d, $4 \mathrm{H}$; quaterrylene), $7.35(\mathrm{~m}, 2 \mathrm{H} ;-\mathrm{O}-\mathrm{Ph}$ H), $7.21(\mathrm{~m}, 12 \mathrm{H} ;-\mathrm{O}-\mathrm{Ph}-\mathrm{H}+\mathrm{Ph}-\mathrm{H}), 7.13(\mathrm{~m}, 8 \mathrm{H} ; \mathrm{Ph}-\mathrm{H}), 2.89\left(\mathrm{~b}, 8 \mathrm{H} ; \mathrm{CH}_{2}\right), 2.58(\mathrm{~s}, 4 \mathrm{H}$; $\mathrm{CH}$ isopropyl), $1.45\left(\mathrm{~s}, 36 \mathrm{H} ; \mathrm{CH}_{3}\right.$ tert.-butyl $), 1.05\left(\mathrm{~d}, 24 \mathrm{H} ; \mathrm{CH}_{3}\right.$ isopropyl). ${ }^{13} \mathrm{C}-\mathrm{NMR}$ (125 MHz, $\mathrm{C}_{2} \mathrm{D}_{2} \mathrm{Cl}_{4}$, spinecho, $\left.\delta\right): 163.49(\mathrm{C}=\mathrm{O}), 156.94(\mathrm{C}=\mathrm{O}), 154.59,154.02,137.23$, $135.63,135.53,134.21,132.63,132.33,131.63,129.28,128.31,126.91,122.79,121.05$, $120.49,120.42,114.47,120.25,79.44,42.15,35.78,29.30$ (CH-isopropyl), $28.76\left(\mathrm{CH}_{3}\right.$ tertbutyl), $24.40\left(\mathrm{CH}_{3}\right.$ isopropyl). MS m/z (FD, $\left.8 \mathrm{kV}\right): 1650.3(100 \%)[\mathrm{M}+]$. Elem. Anal. Calcd. for $\mathrm{C}_{120} \mathrm{H}_{116} \mathrm{~N}_{6} \mathrm{O}_{16} \mathrm{Br}_{2}$ : C, 70.03\%; H, 5.68\%; N, 4,08\%. Found: C, 70,05\%; 5.69\%, $4.05 \%$. UV-vis $\left(\mathrm{CHCl}_{3}\right): \lambda_{\max } / \mathrm{nm}\left(\varepsilon / \mathrm{M}^{-1} \mathrm{~cm}^{-1}\right): 752\left(162.000 \mathrm{M}^{-1} \mathrm{~cm}^{-1}\right)$. 
$N, N^{\prime}$-Bis-(2,6-diisopropylphenyl)-9,18 (or 19)-dibromo-1,6,11,16-tetra[4-(2aminoethyl)phenoxy]quaterrylene-3,4,13,14-tetracarboxylic acid diimide (8). The same procedure as for the synthesis of 5 was followed. Yield: $100 \%{ }^{1} \mathrm{H} \mathrm{NMR}(500 \mathrm{MHz}$, $\left.\mathrm{CDCl}_{3}, \delta\right): 9.79(\mathrm{~d}, 4 \mathrm{H}), 9.50(\mathrm{~s}, 2 \mathrm{H}), 9.21(\mathrm{~d}, 2 \mathrm{H}$; terrylene), $8.24(\mathrm{~d}, 4 \mathrm{H}), 7.41(\mathrm{t}, 2 \mathrm{H} ; \mathrm{Ph}-$ H), 7.34 (d, 8H; Ph-H), 7.28 (d, 4H; Ph-H), 7.00 (d, 8H; Ph-H), $3.20\left(\right.$ b, 8H; $\mathrm{CH}_{2}$ ), 2.75 $\left(\mathrm{m}, 8 \mathrm{H} ; \mathrm{CH}_{2}\right), 2.60$ (s, $4 \mathrm{H}$; $\mathrm{CH}$ isopropyl), $1.05\left(\mathrm{~d}, 24 \mathrm{H} ; \mathrm{CH}_{3}\right.$ isopropyl). ${ }^{13} \mathrm{C}-\mathrm{NMR}(125$ $\mathrm{MHz}, \mathrm{C}_{2} \mathrm{D}_{2} \mathrm{Cl}_{4}$, spinecho, $\left.\delta\right): 163,49(\mathrm{C}=\mathrm{O}), 154.59,154.02,137.23,135.63,135.53$, $134.21,132.63,132.33,131.63,129.28,128.31,126.91,122.79,121.05,120.49,120.42$, $114.47,120.25,42.15,35.78,29.30$ ( $\mathrm{CH}$ isopropyl), $24.40\left(\mathrm{CH}_{3}\right.$ isopropyl). $\mathrm{MS} \mathrm{m} / \mathrm{z}$ (FD, $8 \mathrm{kV}): 1988.9(100 \%)[\mathrm{M}+]$. Elem. Anal. Calcd. for $\mathrm{C}_{100} \mathrm{H}_{84} \mathrm{~N}_{6} \mathrm{O}_{8} \mathrm{Br}_{2}: \mathrm{C}, 72.46 \% ; \mathrm{H}$, $5.11 \% ; \mathrm{N}, 5.07 \%$. Found: C, 71.48\%, H, 5.14\%; N, 5.09\%. UV-vis $\left(\mathrm{CHCl}_{3}\right): \lambda_{\max } / \mathrm{nm}$ $\left(\varepsilon / \mathrm{M}^{-1} \mathrm{~cm}^{-1}\right): 752\left(138.600 \mathrm{M}^{-1} \mathrm{~cm}^{-1}\right)$.

Polymer synthesis and deprotection. Polypeptide synthesis and deprotection were carried out as described earlier[8]. As a representative example, the ${ }^{1} \mathrm{H}-\mathrm{NMR}$ spectroscopy results of the star-shaped polypeptides $9 \mathrm{~b}$ and $11 \mathrm{~b}$ are given below.

9b: ' $\mathrm{H}-\mathrm{NMR}(500 \mathrm{MHz}, \mathrm{DMSO}, \delta): 8.25$ (s, $4.6 \mathrm{H}$; terrylene), 7.25 (b,714 H; Ph- $\underline{\mathrm{H}}+\mathrm{Bn}-$ $\underline{\mathrm{H}}$ ), 6.89 (b, $9.2 \mathrm{H} ; \mathrm{Ph}-\underline{\mathrm{H}}$ ), 5.0 (b, 215.7; Bn- $\underline{\mathrm{C}}_{2}-$ ), 3.9-4.2 (b, 108.2; $\alpha-\mathrm{C} \underline{\mathrm{H}}-$ ), 2.9 (b, $\left.231.4 \mathrm{H} ;-\mathrm{CH}_{2}-\right), 1.4-2.1$ (b, $\left.752.5 \mathrm{H} ;-\mathrm{CH}_{2}-\underline{\mathrm{CH}}_{2}-\right), 1.05$ (b, 24H; - $\underline{\mathrm{H}}_{3}$ isopropyl). Note that, due to the relative long polymers not all the aromatic signals of the chromophores could be analyzed via NMR spectroscopy. 9a,b: UV-vis (DMF): $\lambda_{\max } / \mathrm{nm}\left(\varepsilon / \mathrm{M}^{-1} \mathrm{~cm}^{-1}\right): 683$ $\left(80.300 \mathrm{M}^{-1} \mathrm{~cm}^{-1}\right)$. 10: UV-vis (DMF): $\lambda_{\max } / \mathrm{nm}\left(\varepsilon / \mathrm{M}^{-1} \mathrm{~cm}^{-1}\right): 760\left(170.970 \mathrm{M}^{-1} \mathrm{~cm}^{-1}\right)$.

$11 \mathrm{~b}$ : ${ }^{1} \mathrm{H}-\mathrm{NMR}\left(500 \mathrm{MHz}, \mathrm{D}_{2} \mathrm{O}, \delta\right): 8.23$ (s, 29.7H; Ar-H-terrylene), $4.30(\mathrm{t}, 108 \mathrm{H} ; \mathrm{C} \alpha-\mathrm{H})$, 3.00 (b, $207.6 \mathrm{H},-\mathrm{CH}_{2}-\mathrm{NH}-\mathrm{R}$ ), 1.79 (b, $386.5 \mathrm{H} ;-\mathrm{CH}_{2}-\mathrm{CH}_{2}-$ ), 1.40 (b, $244.8 \mathrm{H},-\mathrm{CH}_{2}{ }^{-}+$ $\mathrm{CH}$ - isopropyl), 1.15 (b, $24 \mathrm{H} ;-\mathrm{CH}_{3}$ isopropyl). $\mathrm{n}$ : number average of $\mathrm{L}$-lysine units per arm. 11a,b: UV-vis $\left(\mathrm{H}_{2} \mathrm{O}\right): \lambda_{\max } / \mathrm{nm}\left(\varepsilon / \mathrm{M}^{-1} \mathrm{~cm}^{-1}\right): 701\left(57.000 \mathrm{M}^{-1} \mathrm{~cm}^{-1}\right)$. 12: UV-vis $\left(\mathrm{H}_{2} \mathrm{O}\right)$ : $\lambda_{\text {max }} / \mathrm{nm}\left(\varepsilon / \mathrm{M}^{-1} \mathrm{~cm}^{-1}\right): 768\left(99.400 \mathrm{M}^{-1} \mathrm{~cm}^{-1}\right)$.

\section{Results and discussion}

Synthesis of the initiators. The synthesis of the amino functionalized rylene derivatives 5 and $\mathbf{8}$ is depicted in Scheme 1. The preparation of $\mathbf{5}$ starts with the phenoxylation of tetrabromoterrylenediimide $\mathbf{1}$ with an excess of $\mathbf{3}$ to afford the tert.-butoxycarbonyl (BOC) protected intermediate 4 . The optimum reaction temperature was found to be $90^{\circ} \mathrm{C}$, at which 4 was obtained in $80 \%$ yield. Finally, the desired tetra-amino terrylene 5 was obtained in quantitative yield by treatment of 4 with trifluoracetic acid (TFA).

Interestingly, phenoxylation of 6 mainly afforded the four-fold tyramine substituted chromophore 7. Tetrafunctionalization was promoted by the two imide structures, which increase the reactivity of the four peripheral bromines. The two central bromines are less reactive and remained unaffected, even under stronger conditions such as prolonged reaction times or higher temperatures. In a final step, the tetra-amino quaterrylene derivative 8 was obtained in quantitative yield after deprotection of the BOC groups using trifluoroacetic acid. 


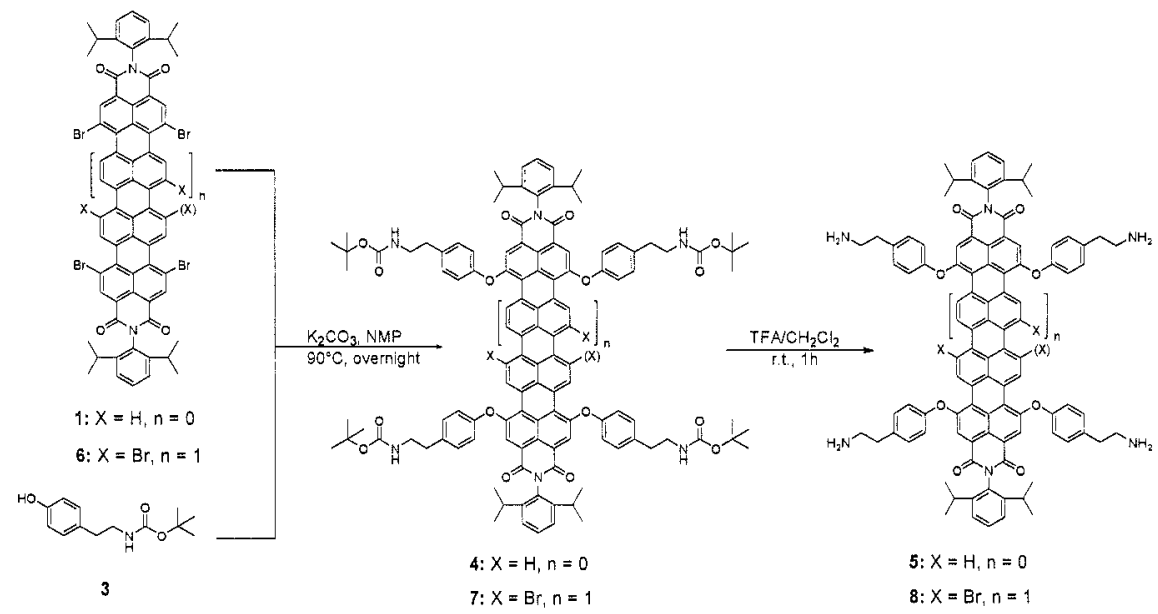

Scheme 1

Polymerization and deprotection. Terrylenediimide 5 and quaterrylenediimide 8 were employed as initiators for the ring-opening polymerization of $\mathrm{N}^{\varepsilon}$-benzyloxycarbonyl-Llysine N-carboxyanhydride (Z-Lys NCA) (Scheme 2). Peptide chain length was controlled via the molar ratio of monomer (Z-Lys NCA) to initiator ( 5 or $\mathbf{8}$ ). Using terrylene $\mathbf{5}$, two polymerization experiments were performed, targeting at star polymers with number average arm lengths of 50 and 100 monomers. Quaterrylene 8 was used for the synthesis of a star polymer with an anticipated arm length of 100 repeat units. In a final step, the resulting Z-Lys star polypeptides were treated with $\mathrm{HBr} / \mathrm{AcOH}$ to remove the Z-protective groups, yielding the L-lysine based star polypeptides $11 \mathrm{a} / 11 \mathrm{~b}$ and 12 . The polypeptides were characterized by ${ }^{1} \mathrm{H}-\mathrm{NMR}$ spectroscopy and gel-permeation chromatography (GPC). The results of these experiments are summarized in Table 1.

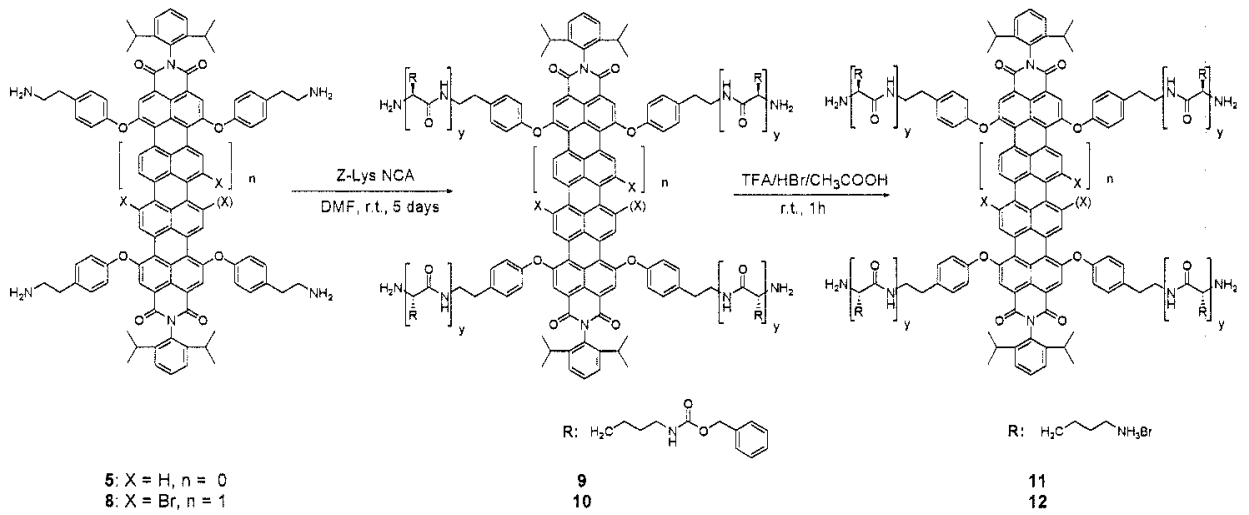

Scheme 2 
Table 1. Molecular characteristics of the terrylene and quaterrylene based polypeptide star polymers.

\begin{tabular}{cccccccccc} 
\# & Initiator & $\mathrm{n}_{\mathrm{th}}{ }^{\mathrm{a}}$ & Yield $^{\mathrm{b}}$ & ${ }^{\mathrm{l}} \mathrm{H}-\mathrm{NMR}^{\mathrm{c}}$ & \multicolumn{3}{c}{$\mathrm{GPC}^{\mathrm{f}}$} \\
& & & & $(\%)$ & $\mathrm{n}^{\mathrm{d}}$ & $\mathrm{M}_{\mathrm{n}}(\mathrm{g} / \mathrm{mol})^{\mathrm{e}}$ & $\mathrm{M}_{\mathrm{n}}(\mathrm{g} / \mathrm{mol})^{\mathrm{g}}$ & $\mathrm{n}^{\mathrm{h}}$ & $\mathrm{M}_{\mathrm{w}} / \mathrm{M}_{\mathrm{n}}{ }^{\mathrm{l}}$ \\
$\mathbf{9 a} / \mathbf{1 1 a}$ & $\mathbf{5}$ & 50 & 76 & 68 & 73200 & 16200 & 14 & 1.5 \\
$\mathbf{9 b} / \mathbf{1 1 b}$ & $\mathbf{5}$ & 100 & 69 & 108 & 118900 & 32300 & 29 & 1.6 \\
$\mathbf{1 0} / \mathbf{1 2}$ & $\mathbf{8}$ & 100 & 85 & 119 & 127100 & 35700 & 31 & 1.8
\end{tabular}

"Theoretical arm-length $\left(\mathrm{n}_{\mathrm{t}}\right)$ calculated from: $[N C A] /(4 \times[5])$ or $[N C A] /(4 \times[8])$. ${ }^{b}$ Isolated yield of the Z-Lys star polymers after precipitation and vacuum drying. 'NMR data refer to experiments carried out with the L-lysine star polypeptides, which were analyzed in $\mathrm{D}_{2} \mathrm{O}$. ${ }^{\mathrm{d}}$ Arm length obtained by comparison of the integral of the terrylene/quaterrylene isopropyl $-\mathrm{CH}_{3}$ group with that of the $\alpha-\mathrm{CH}$ protons of the peptide arm. "Number-average molecular weight of the star polypeptides, calculated from the ${ }^{1} \mathrm{H}-\mathrm{NMR}$ results. ${ }^{\mathrm{f}}$ Performed in DMF-solution using a UV-vis detector at $270 \mathrm{~nm}$. ${ }^{\mathrm{B}} \mathrm{Number}-$ average molecular weight. "Number-average degree of polymerization. ${ }^{\text {Th }}$ Polydispersity.

Table 1 shows that the number average arm lengths are in relatively good agreement with the calculated numbers, which is typical for primary amine initiated NCA polymerizations.[8,9] The molecular weights determined by GPC are significantly lower than those obtained from ${ }^{1} \mathrm{H}-\mathrm{NMR}$ spectroscopy. Both the difference in chemical composition and in topology between the star polypeptides and the linear poly(ethylene glycol) samples that were used as GPC calibration standards may contribute to this underestimation. Typically, star polymers of a given molecular weight have a more compact solution conformation and elute later from the GPC column than their linear analogs.[8]

$U V$-vis characterization and photostability. The optical properties of the star polypeptides were investigated by UV-vis spectroscopy, both in organic media and in aqueous solution. UV-vis spectra of perylene, terrylene and quaterrylene based Z-Lys star polypeptides measured in DMF are shown in Figure 1(a). The absorption maxima are located at $581 \mathrm{~nm}$, $677 \mathrm{~nm}$ and $752 \mathrm{~nm}$ for the perylene, terrylene and quaterrylene derivatives, respectively. The UV spectra are well resolved in all cases and show a second relative maximum at shorter wavelength. UV-vis spectra recorded from aqueous solutions of the corresponding perylene, terrylene and quaterrylene based L-lysine star polymers with a number average arm length of 100 repeat units are shown in Figure 1(b). In comparison with Figure 1(a), the absorption maxima are bathochromically shifted $(10-20 \mathrm{~nm})$, which is probably due to the different environment in which the highly hydrophobic chromophores are submerged. The fine-structure of the spectra has also changed and in case of the quaterrylene polypeptide star the second absorption maximum has almost disappeared. This effect may be due to two main factors; the hydrophilicity of the core environment and the extension of the $\pi$ system of the chromophore, which may promote aggregation. The extinction coefficients, however, remain high, also in water: $57.000 \mathrm{M}^{-1} \mathrm{~cm}^{-1}$ for the terrylene star polymers and $99.000 \mathrm{M}^{-1} \mathrm{~cm}^{-1}$ for the quaterrylene based polypeptides. These high extinction coefficients allow the use of very small concentrations of the rylene polypeptides, which is advantageous for potential applications in the biomedical field. 

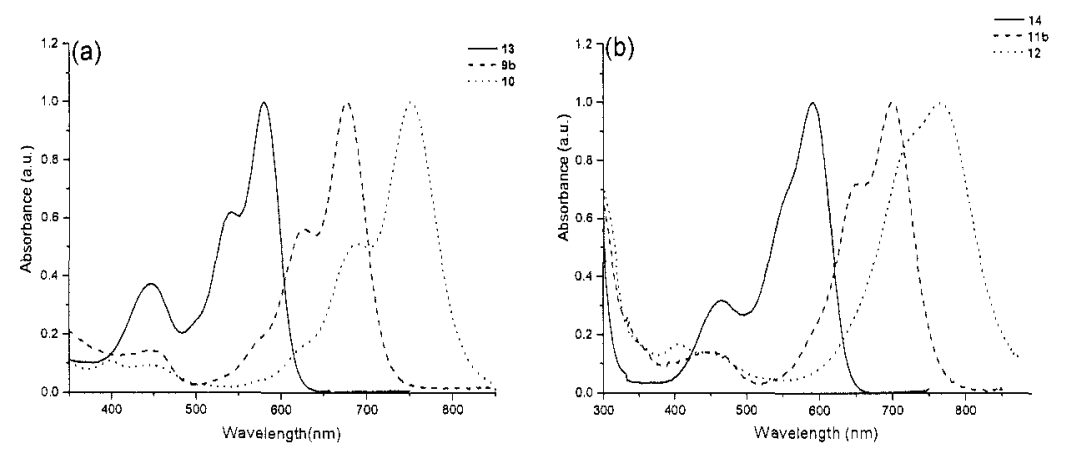

Figure 1. UV-vis absorption spectra of different star shaped polypeptides obtained using perylene (13, resp. 14), [8] terrylene and quaterrylene derivatives as initiators for the ring-opening polymerization of Z-Lys NCA. In all cases the arm length is $\sim 100$ units. The spectra shown in Figure 1(a) were obtained using the side chain protected star polypeptides and were recorded in DMF. Figure 1(b) shows the UV-vis spectra of the deprotected star poly(L-lysine $\mathrm{HBr}$ )s in $\mathrm{H}_{2} \mathrm{O}$ at $\mathrm{pH}=7$.

As mentioned before, rylene dyes are attractive because of their high chemical and photochemical stability. The experiments discussed so far already provided indirect proof for the chemical stability of the dyes. Both basic $\left(\mathrm{K}_{2} \mathrm{CO}_{3}\right)$ and strongly acidic reaction conditions $\left(\mathrm{CF}_{3} \mathrm{COOH}\right)$ did not affect the optical properties of the rylene dyes. In an additional series of experiments, the photochemical stability of the peptide modified terrylene and quaterrylene dyes was studied. These studies needed to be performed carefully, since photochemical stability is not only an intrinsic property of the dye, but also depends on external factors, such as e.g. the solvent, the light spectrum and the ambient atmosphere.[10] To assess the photochemical stability of the peptide modified terrylene and quaterrylene chromophores, aqueous solutions of $11 \mathrm{~b}$ and 12 were exposed to $365 \mathrm{~nm}$ UV-light for an 8 day period. Figure 2 shows the UV-vis spectra of the samples taken at regular intervals during the UV exposure. After 8 days of UV illumination, the absorbance of the quaterrylene based polypeptide is still $80 \%$ of that of the original solution. The terrylene based polypeptide is even less affected by UV irradiation and still has $95 \%$ of its original absorbance after 8 days. These experiments demonstrate that even in polar aqueous solutions, the terrylene and quaterrylene dyes possess high photochemical stabilities.

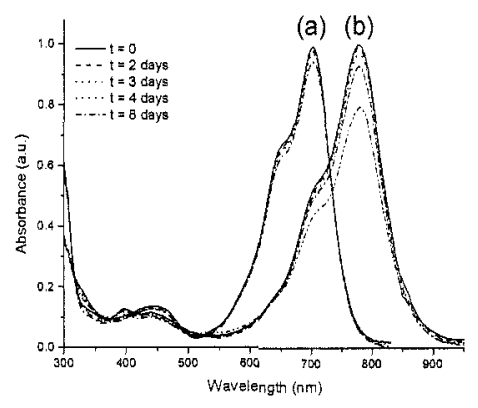

Figure 2. Time dependence of the UV-vis absorption spectra of aqueous solutions ( $c=14 \mathrm{mg} / \mathrm{mL}$ ) of (a) terrylene (11 b) and (b) quaterrylene star polypeptide (12) exposed to $365 \mathrm{~nm}$ UV light. 


\section{Conclusions}

In this contribution, we have reported a new synthetic strategy for the preparation of watersoluble NIR absorbing dyes. The synthesis starts with the preparation of amino functionalized terrylene and quaterrylene chromophores, which were obtained in 3 high yielding steps from terrylene and quaterrylene. The amino-functionalized rylene dyes were subsequently used as initiators for the ring-opening polymerization of Z-Lys NCA. Removal of the $\mathrm{Z}$ protective groups from the resulting $\mathrm{Z}$-Lys star polymers afforded watersoluble peptide-modified NIR absorbing terrylene and quaterrylene chromophores. These novel NIR absorbing star polypeptides possess high extinction coefficients and high photochemical stabilities. To obtain more insight into the photophysics of the title compounds, single molecule spectroscopy studies are presently being performed.

Acknowledgements. This work was financially supported by the Deutsche Forschungsgemeinschaft (Sonderforschungsbereich 625 and Emmy Noether-Program) and BASF AG (Ludwigshafen, D).

\section{References}

1. (a) Fabian J, Nakazumi H, Matsuoka M (1992) Chem Rev 92:1197. (b) Fabian J, Zahradník R (1989) Angew Chem 101:693

2. Geerts Y, Quante H, Platz H, Mahrt R, Hopheimer M, Böhm A, Müllen K (1998) J Mater Chem 8:2357

3. (a) Holtrup FO, Müler GRJ, Quante H, De Feyter S, De Schryver FC, Müllen K (1997) Chem Eur J 3(2):219. (b) Quante H, Müllen K (1995) Angew Chem 107(12):1487. (c) Geerts Y, Quante H, Platz H, Mahrt R, Hopheimer M, Böhm A, Müllen K (1998) J Mater Chem 8(11):2357

4. Perylene diimides are known to be excellent thermal and photostable sensitizers. (a) Icli S, Demic S, Dindar B, Doroschenko AO, Timur C (2000) J Photochem Photobiol A: Chem 136.15. (b) Langhals A (1995) Heterocycles 40(1):477

5. Qu J, Reuther E, Müllen K, manuscript in preparation.

6. Nutt RF, Chen KM, Joullié MM (1984) J Org Chem 49:1013.

7. Poché DS, Moore MJ, Bowles JL (1999) Synth Commun 29:843

8. Klok H-A, Rodríguez-Hernández J, Becker S, Müllen K (2001) J Polym Sci Part A Polym Chem 39:1572

9. (a) Kricheldorf HR $\alpha$-amino acid $\mathrm{N}$-carboxyanhydrides and related heterocycles, Springer-Verlag, Berlin, 1987. (b) Deming TJ (1997) Adv Mater 9:299; (c) Deming TJ (2000) J Polym Sci Part A Polym Chem 38:3011.

10. Seybold G, Wagenblast G (1989) Dyes Pigm 11:303 